\title{
Adaptation and validation of a questionnaire measuring knowledge, awareness and practice regarding familial hypercholesterolaemia among primary care physicians in Malaysia
}

Ahmad Baihaqi Azraii

Universiti Teknologi MARA

Anis Safura Ramli ( $\square$ rossanis_yuzadi@yahoo.co.uk)

Institute of Pathology, Laboratory and Forensic Medicine (I-PPerForM), Universiti Teknologi MARA

(UiTM) https://orcid.org/0000-0002-9517-1413

Zaliha Ismail

Universiti Teknologi MARA

Suraya Abdul-Razak

Universiti Teknologi MARA

Siti Fatimah Badlishah-Sham

Universiti Teknologi MARA

Noor Alicezah Mohd-Kasim

Universiti Teknologi MARA

Norsiah Ali

Universiti Teknologi MARA

Gerald F Watts

University of Western Australia

Hapizah Nawawi

Universiti Teknologi MARA

Research article

Keywords: familial hypercholesterolaemia, knowledge, awareness and practice, questionnaire validation, primary care, Malaysia

Posted Date: October 28th, 2019

DOI: https://doi.org/10.21203/rs.2.16498/v1

License: (c) (i) This work is licensed under a Creative Commons Attribution 4.0 International License. Read Full License 
Page $2 / 29$ 


\section{Abstract}

Background: Primary care physicians (PCP) play an important role in early detection of Familial Hypercholesterolaemia (FH). However, knowledge, awareness and practice (KAP) regarding FH among Malaysian PCP are not well established, and there was no validated tool to assess their FH KAP. Therefore, this study aimed to adapt an FH KAP questionnaire and to determine its validity and reliability among Malaysian PCP.

Methods: This cross-sectional validation study involved PCP with $\geq 1$-year working experience in the Malaysian primary care settings. In Phase 1, the original 19-item FH KAP questionnaire was content validated and adapted by 7 experts. The questionnaire was then converted into an online survey instrument and was face validated by 10 PCP. In Phase 2, the adapted questionnaire was distributed via e-mail to 1500 PCP for self-administration. Data were collected on their KAP, demography, qualification and work experience. The construct validity was tested using known-groups validation method. PCP with postgraduate qualification (PCP-PG-Qual) were hypothesized to have better FH KAP compared with PCP without postgraduate qualification (PCP-noPG-Qual). The internal consistency reliability was tested using Kuder Richardson formula-20 (KR-20) and test-retest reliability was tested on 26 PCP using kappa statistics.

Results: During content validation and adaptation, 10 items remained unchanged, 8 items were modified, 1 item was moved to demography and 7 items were added. The adapted questionnaire contained 25 items (11 knowledge, 5 awareness and 9 practice items). A total of 130 out of 1500 PCP (response rate: $8.7 \%)$ completed the questionnaire. The mean percentage knowledge score was significantly higher in PCP-PG-Qual compared to PCP-noPG-Qual (53.5, SD \pm 13.9 vs. $35.9, S D \pm 11.79), t(128)=6.90, p<0.001$. The median percentage awareness score was significantly higher in PCP-PG-Qual compared to PCP-noPGQual (15.4, lqR \pm 23.08 vs. 7.7, IqR \pm 15.38$), p=0.030$. The mean percentage practice score was significantly higher in PCP-PG-Qual compared to PCP-noPG-Qual (69.2, SD \pm 17.62 vs. 54.4, $S D \pm 19.28), t(128)=3.79$, $p<0.001$. The KR-20 was 0.79 (moderate reliability) and average Kappa was 0.796 (substantial agreement).

Conclusion: The robust validation methods and findings suggest that the adapted 25 -item questionnaire is a valid and reliable tool to measure FH KAP among Malaysian PCP. This would aid to improve FH care in the community.

\section{Background}

Familial Hypercholesterolaemia (FH) is a genetic disorder characterized by severely elevated low density lipoprotein cholesterol (LDL-c) that leads to atherosclerosis, resulting in an increased risk for premature coronary artery disease (CAD) [1, 2]. It is one of the most common forms of inherited conditions with an autosomal mode of inheritance [2]. Mutations in several genes such as LDLR, APOB100 and PCSK9 have been strongly linked to FH [2]. Clinically, this condition presents in the form of either heterozygous FH 
$(\mathrm{HeFH})$ or homozygous $\mathrm{FH}(\mathrm{HoFH})$. HeFH is more common with an estimated $70-90 \%$ of $\mathrm{FH}$ cases resulting from heterozygous pathogenic variants $[2,3]$. HeFH accounts for $2-3 \%$ of $C A D$ in individuals below 60 years of age $[1,3]$. In contrast, most individuals with HoFH experience severe CAD by their mid20 s and the rate of either death or coronary bypass surgery by the teenage years is very high $[1,3]$. Early detection and treatment of $\mathrm{FH}$ through cholesterol-lowering therapies can effectively prevent premature CAD [4].

Globally, the prevalence of HeFH is estimated to be 1 in 200 to 1 in 500 in various populations [5-7]. In Malaysia, the prevalence of clinically diagnosed FH has been reported at 1 in 100 , which is one of the highest in the world [8]. Therefore, with a population of 32 million, it is estimated that 320,000 individuals may be affected by HeFH [8]. However, like in most countries, the majority of these cases are still undiagnosed, resulting in lost opportunities to prevent premature $\operatorname{CAD}[9,10]$. This has undoubtedly contributed to the high prevalence of premature CAD among Malaysians which accounted for $10-15 \%$ of acute coronary syndrome (ACS) [11]. A recent national report found that the mean age of individuals with ACS at admission in Malaysia was 58.6 years old, of which $23.8 \%$ were under the age of 50 years [12]. This is younger compared with our Asian counterparts in neighbouring countries [12, 13].

Improving identification of $\mathrm{FH}$, particularly in primary care, enables early treatment of these individuals which is crucial to reduce their risk of premature CAD [14]. In Malaysia, primary care physicians (PCP) are well positioned in the front line of primary care service which is delivered by the public and private sectors [15]. They are already managing common cardiovascular risk factors such as diabetes, hypertension and hypercholesterolaemia [16]. However, only a handful of PCP in Malaysia hold formal postgraduate (PG) qualification in primary care, while the majority do not $[15,16]$. The situation in Malaysia is similar to many other developing countries where doctors without primary care qualification are allowed to practice as PCP [17]. This is in contrast to some developed countries such as the United Kingdom (UK) and Australia where PCP are required to have mandatory PG training and qualification in primary care.

Numerous studies have shown that there were gaps in knowledge, awareness and practice (KAP) regarding FH among PCP in various parts of the world [18-25], especially in developing countries [25]. Pang et al. recently assessed FH KAP among PCP in several Asia-Pacific countries in the 'Ten Countries Study' [25]. Their KAP have been found to be suboptimal where less than half of the PCP were aware of FH clinical guidelines; and their knowledge of prevalence, inheritability, diagnostic criteria and CAD risk of FH were also found to be low [25]. Addressing these gaps is essential for effective implementation strategies to improve management of FH among PCP [26].

In the FH 'Ten Countries Study', the 19-item FH KAP questionnaire designed by Bell et al. in 2014 [18] was utilized to assess the FH KP among PCP [25]. This questionnaire was initially developed with the aim to determine the KAP regarding FH among PCP in Western Australia [18]. Since then, this questionnaire has been validated and tested in several populations including the UK [21, 22], India [23] and Saudi Arabia [24]. Although the FH 'Ten Countries Study' already included 219 Malaysian PCP [25], little is known regarding the gaps in KAP between PCP with PG qualification and those without. To further extend this 
finding, there was a need to adapt and validate this questionnaire among the Malaysian PCP, comparing the two groups. Therefore, the objectives of this study were to adapt the 19-item FH KAP questionnaire into the local setting and to determine its validity and reliability among the Malaysian PCP with and without PG qualification. The ultimate aim was to utilize this tool to improve awareness and skills among PCP as part of a national implementation strategy for improved detection and care of $\mathrm{FH}$ in the community.

\section{Methods}

This study was undertaken under the aegis of the FH 'Ten Countries Study' which investigated several pertinent areas of FH care in the Asia-Pacific Region [25]. It was conducted in two parts. The first part involved adaptation and validation of the FH KAP questionnaire; and the second part was determination of the FH KAP among Malaysian PCP using the adapted and validated questionnaire. This paper presents the detailed methods and findings of the first part of the study. The second part of the study and its results was already published in 2018 [27]. The sampling for the first and second parts was mutually exclusive i.e. participants who were recruited in the first part of the study were excluded from the second part.

\section{Study design and participants}

This was a cross-sectional questionnaire validation study conducted in two phases. Phase 1 was the content validation, adaptation and face validation of the FH KAP questionnaire. Phase 2 was the field testing and psychometric evaluation.

This study was conducted between January 2016 and January 2017 among a group of PCP in Malaysia consisted of Medical Officers (MO), General Practitioners (GP) and Family Medicine Specialists (FMS). Those registered with Malaysian Medical Council and have one or more years of working experience in the Malaysian primary care settings were included. Those who were working as locum doctors in primary care clinics or those who were from medical specialties other than family medicine were excluded.

PCP with postgraduate qualification (PCP-PG-Qual) was defined as those who have completed formal PG training i.e. Diploma in Family Medicine (DFM), Master of Family Medicine, Fellow of the Royal Australian College of General Practitioners (FRACGP), and Member of the Royal College of General Practitioners, United Kingdom (MRCGP, UK). PCP without postgraduate qualification (PCP-noPG-Qual) was defined as those working in primary care with basic medical degree such as Bachelor of Medicine, and Bachelor of Surgery (MBBS) and Doctor of Medicine (MD).

In Phase 2, the psychometric evaluation involved construct validity and reliability testing. Construct validity was conducted by testing differences between two groups with expected differences to establish known-groups validity [28]. PCP-PG-Qual was hypothesized to have better KAP regarding FH compared to PCP-noPG-Qual. Reliability testing involved internal consistency analysis using Kuder Richardson 
formula-20 (KR-20) reliability coefficient [29]; and test-retest reliability using Cohen's kappa statistics to measure the stability of the responses to the questionnaire over time [30]. Figure 1 outlines the two phases of the adaptation and validation processes.

\section{PLEASE INSERT FIGURE 1 HERE}

\section{Study instrument}

The FH KAP questionnaire used in this study was originally designed by Bell et al. [18]. Written permission to adapt and validate the questionnaire was obtained from the questionnaire developer via e-mail prior to the conduct of the study. The questionnaire was developed in the English language and consisted of 19 items divided into three domains i.e. knowledge, awareness and practice. The questionnaire items and responses were presented in various forms which included 7-point Likert scale, single best answer, multiple answer, 'Yes/ No/ Don't know' and free text answer. Most of the questions have predetermined correct answers.

There were seven items in the knowledge domain covering the following areas: i) description of $\mathrm{FH}$; ii) identification of lipid profile in $\mathrm{FH}$; iii) prevalence of $\mathrm{FH}$ in Australia; iv) inheritance of $\mathrm{FH}$ in first-degree relatives; v) $\mathrm{CAD}$ risk in untreated $\mathrm{FH}$; vi) age threshold for premature $\mathrm{CAD}$; vii) role of genetic testing in $\mathrm{FH}$. The awareness domain consisted of three items covering the following areas; i) familiarity with $\mathrm{FH}$; ii) Australian clinical guideline on $\mathrm{FH}$; iii) lipid specialist service. There were nine items in the practice domain covering the following areas; i) assistance in FH detection; ii) number of FH cases under care; iii) screening of relatives in $\mathrm{FH}$ cases; iv) family screening of $\mathrm{FH}$ among premature CAD; v) preference on effective healthcare provider in $\mathrm{FH}$ detection; vi) age for $\mathrm{FH}$ screening among young individuals in a family with premature CAD; vii) referral of $\mathrm{FH}$ patients to lipid specialist; viii) pharmacological agents used in hypercholesterolaemia; ix) combination of pharmacological agents used in severe hypercholesterolaemia.

\section{Phase 1: Content validation, adaptation and face validation}

\section{Content validation and adaptation}

The content validation involved seven experts, consisting of three FMS who were familiar with clinical care and management of $\mathrm{FH}$, three chemical pathologists who run a lipid specialist clinic and one public health physician who had broad experience in questionnaire validation process. The panel of experts reviewed the original 19-item FH KAP questionnaire for conceptual and item equivalence. The panel reviewed the relevance of each questionnaire item and ascertained whether the contents were appropriate to the study objectives and the local context. The questionnaire was not translated into the Malay language because most doctors in Malaysia including PCP are proficient in English. 


\section{Conversion of the questionnaire into an online survey instrument}

The adapted paper-based FH KAP questionnaire was then converted into an online survey questionnaire using the Google ${ }^{\circledR}$ Forms [31]. Relevant information about the study was given on the first page of the online survey and also in the email containing the link to the survey. The information given was the same as the paper-based information sheet, containing the identity of the researchers, contact details, the reason for conducting the survey and how the data would be used. The study information sheet also highlighted the right of the participants to anonymously and voluntarily participate in the study and the right to withdraw from the study at any time without any reason and without penalty. Informed consent was obtained via the online questionnaire when the respondent had to click the 'Consent' button before the next page of the questionnaire could be accessed.

The questionnaire was divided into three sections. Section A contained questions on the inclusion and exclusion criteria. Participants could only proceed to Section B and C, if they fulfil the eligibility criteria. Section B contained questions covering the KAP domains. Section $\mathrm{C}$ included questions on demographic characteristic, qualification and work experience. Participants could omit to answer any of the items as none of them required an obligatory response (other than those relating to the consent) before they could proceed until the end of the questionnaire.

\section{Face validation}

Face validation of the adapted FH KAP questionnaire was conducted among 10 PCP who fulfilled the inclusion and exclusion criteria, and who were naive to the study. The 10 PCP were given both the paperbased and online versions of the questionnaire. The questionnaire was self-administered, and participants were requested to take note of the time taken to answer the questionnaire, clarity of the content, language and wording used and the general structure of the questionnaire. Their opinions on understanding the instructions, contents, wording and general structure of the questionnaire were assessed and recorded. The result was discussed among the panel of experts. Minor correction and fine tuning of the questionnaire were addressed according to their comments and suggestions.

\section{Phase 2: Field testing and psychometric evaluation}

The adapted FH KAP online questionnaire was field tested amongst PCP who fulfilled the same inclusion criteria as in Phase 1. However, PCP who participated in Phase 1 and 2 were mutually exclusive, as those who participated in Phase 1 were not recruited for Phase 2.

\section{Sample size}

Two sample sizes were calculated for this study, one for the known-groups validity and the other for the reliability testing. The known-groups validity compared mean or median percentage score of FH KAP 
between PCP-PG-Qual and PCP-noPG-Qual. Therefore, the sample size for each group was calculated using the OpenEpi software for comparison of two means formula [32]. As there was no previous study comparing KAP between PCP-PG-Qual and PCP-noPG-Qual related to FH, the calculation was therefore made based on the previous study by Mosli et al., which compared KAP regarding colorectal cancer screening among two groups of PCP in Saudi Arabia [33]. Family Medicine trained physicians had higher mean knowledge score compared to physicians with MBBS only $(4.93 \pm 2.29$ vs. $3.23 \pm 1.88, P<0.01)$ [33]. Based on the difference between the two means in this study, $95 \%$ Confidence Interval ( 2 sided), $80 \%$ power and a ratio of 1:1 between groups, the minimum sample size required for each group was 24 participants.

The sample size for the internal consistency reliability analysis using KR-20 was calculated based on the subject to item ratio for which a subject to item ratio of 5:1 was used [29]. Therefore, a minimum of 125 participants were needed $(25$ items $\times 5=125)$. Considering estimated response rate of $10-30 \%$ for an online survey [34], the questionnaire was planned to be distributed to at least 1500 participants.

Regarding test-retest reliability, sample size for testing the Cohen's kappa agreement was determined to be 26 , which was $20 \%$ of the total number of participants [35].

\section{Sampling method}

A link to access the adapted FH KAP online questionnaire was sent via email to 1500 PCP in the e-mail lists of two major professional bodies for PCP in Malaysia. The email contained information on the study background, purpose and benefits, participation in the study, study procedure, confidentiality as well as informed consent. They were invited to open a link to the online questionnaire.

The questionnaire consisted of three sections as previously described. Those who consented to the study and fulfilled the study inclusion and exclusion criteria in Section A were able to proceed to Section B and $\mathrm{C}$ of the online form. Once the questionnaire was completed and submitted, no modification was allowed. The participants had the right to withdraw from the study at any time without penalty. To avoid repeated response from the same participant, the questionnaire contained an item asking whether they have answered the questionnaire previously. For test-retest reliability testing, those who have responded were contacted via e-mail to obtain their second response after two weeks of their first response.

\section{Questionnaire interpretation, coding and scoring}

For item no. 1 which assessed FH familiarity, Likert scale scores of 1 to 4 were interpreted as 'unfamiliar' and coded as ' 0 ' while scores of 5 to 7 were interpreted as 'familiar' and coded as ' 1 '. The interpretation was done in accordance to the study by Rangarajan et al. [23] and Pang et al. [25]. For all of the items that have predetermined correct answers, incorrect response was coded as ' 0 ' while correct response was coded as ' 1 '. The questionnaire scoring was determined based on the study by Batais et al. [24] by summing up the correct responses of the items in each KAP domain. The possible minimum to maximum 
score for each participant ranged from 0 to 19 for knowledge, 0 to 13 for awareness, and 0 to 9 for practice domains. The maximum score for each domain was not similar with the number of items because some of the questions had multiple correct answers and thus, they were scored accordingly for each correct response. The actual score for each domain was then converted into percentage score for ease of comparison between the domains. Scores of $50 \%$ or more for each domain were considered acceptable $[24,25]$. The scoring method of the adapted FH KAP questionnaire is described in Supplementary File 1.

\section{Construct validation}

The construct validity of the adapted FH KAP questionnaire was conducted using known-groups validation method in view of the dichotomous nature of the questionnaire responses rather than numerical or continuous form [28]. The questionnaire would be considered valid if it is able to significantly discriminate across groups of subjects that have been predicted or 'known' to differ from each other [28]. In this study, PCP-PG-Qual was hypothesized to have better KAP regarding FH compared to PCP-noPG-Qual. Therefore, the FH KAP questionnaire would be considered valid if it could significantly discriminate the mean or median FH KAP scores between the two groups.

\section{Reliability testing}

With regards to the internal consistency reliability testing of the adapted FH KAP questionnaire, KR-20 reliability coefficient which is a special form of Cronbach's alpha was carried out in view of the dichotomous nature of the questionnaire's responses [29]. KR-20 reliability coefficient of $<0.50$ was interpreted as low, $0.50-0.80$ was considered moderate and $>0.80$ was interpreted as high [29].

For the test-retest reliability, 26 participants (20\%) were requested to answer the questionnaire again after two weeks interval. Cohen's kappa statistics, which is a robust statistical method, was used for the reliability testing because of the dichotomous nature of the questionnaire responses [30]. The kappa result was interpreted as follows: values $\leq 0$ indicated no agreement, $0.01-0.20$ as none to slight, 0.21 0.40 as fair, $0.41-0.60$ as moderate, $0.61-0.80$ as substantial, and $0.81-1.00$ as almost perfect agreement [30].

\section{Statistical analysis}

Data were analysed using the SPSS software version 24.0 (SPSS Inc., Chicago, IL, USA). Missing data were treated using discrete value. Descriptive statistics were performed to depict the demographic background and practices information of the participants. Data were reported and presented as frequency and percentage. Before conducting the known-groups validity testing of FH KAP between PCPPQ-Qual and PCP-noPG-Qual, normality of data distribution and equality of variance were examined. For the normally distributed data, independent $t$-test was applied to compare the mean percentage score of 
FH KAP between the 2 PCP groups, and for the non-normally distributed data, Mann Whitney u-test was applied. The statistically significance difference between the two groups was reported using P-value of < 0.05. For the internal consistency reliability testing, the KR-20 coefficient [36] for each KAP domain and the overall KR-20 coefficient were calculated. For the test-retest reliability testing using Cohen's kappa statistics [30], the kappa value of each KAP item and the average kappa value were calculated.

\section{Ethical considerations}

The ethical approval for this study was obtained from the Research Ethics Committee (REC), Universiti Teknologi MARA (600-IRMI (5/1/6). The designing of the online survey questionnaire using the Googleß Forms complied with the British Psychological Society Ethics Guidelines for Internet-Mediated Research, 2013 [37]. The study information provided on the first page of the questionnaire highlighted the right of the participants to withdraw from the study at any time without any reason and without penalty. Informed consent was obtained via the online questionnaire when the respondent had to click the 'Consent' button before the next page of the questionnaire could be accessed. Participants could omit to answer any of the items as there was no item (other than those relating to the consent) required an obligatory response before they could proceed until the end of the questionnaire. The survey was made anonymous by switching the option to collect computer IP addresses to 'No'. To ensure confidentiality, the password to the Google ${ }^{\circledR}$ Forms account was only known to the researcher and data were not stored within a shared account.

\section{Results}

\section{Content validation, adaptation and face validation}

During the content validation and adaptation process, a consensus decision was made by the panel of experts whereby 10 items remained unchanged, one item needed to be moved to the demography section, eight items were modified or rephrased to suit the local primary care settings and to ensure better understanding among Malaysian PCP; and seven new items were added. The additional items assessed wider areas of the FH KAP and increased the breadth of the questionnaire. The adapted and face validated FH KAP questionnaire consisted of 25 items and it remained in the English language. Table 1 summarizes the adaptation and modification made to the original 19-item FH KAP questionnaire. Further detail of the adaptation is provided in Supplementary File 2.

\section{PLEASE INSERT TABLE 1 HERE}

Ten PCP face validated the paper-based and the online versions of questionnaire. They found that the questionnaire items were relevant in terms of content and were appropriately placed in the three domains. The language and wording used was clear and general structure and layout of both paper-based and the online versions were attractive. The time taken to answer the questionnaire was approximately 15 
minutes. Minor correction and fine tuning of the questionnaire was done by the panel of experts, taking into consideration the comments and suggestions made by the PCP.

\section{Field testing and psychometric analysis}

Out of 1500, a total of 130 PCP who fulfilled the eligibility criteria responded and completed the online questionnaire giving a response rate of $8.7 \%$. The demographic and practice details of the participants are shown in Table 2. Out of 130 participants, 31 (23.8\%) were PCP-PG-Qual and 99 (76.2\%) were PCPnoPG-Qual. Both groups were comparable in terms of gender distribution, employer and practice locations. The main difference between the two groups was their medical qualifications. Out of 31 PCPPG-Qual, 15 (48.4\%) had DFM, 15 (48.4\%) had Master of Family Medicine, and 1 (3.2\%) had FRACGP certification. Majority $(70.7 \%)$ of the PCP worked in urban areas.

\section{PLEASE INSERT TABLE 2 HERE}

\section{Construct validity using known-groups validation}

The data for knowledge and practice score were normally distributed hence independent $t$ test was used to compare the mean percentage scores, and the data for awareness score were not normally distributed thus Mann Whitney u-test was applied to compare the median percentage scores.

Regarding knowledge, the mean percentage score was significantly higher in PCP-PG-Qual (53.5, SD \pm 13.9) compared to PCP-noPG-Qual $(35.9, S D \pm 11.79), t(128)=6.90, p<0.001$. The difference in the mean percentage score in knowledge regarding $\mathrm{FH}$ between the two groups was 17.54 (95\% $\mathrm{Cl}: 12.52,22.57)$. Regarding practice, the mean percentage score was significantly higher in PCP-PG-Qual (69.2, SD \pm 17.62) compared to PCP-noPG-Qual (54.4, SD \pm 19.28$), t(128)=3.79, p<0.001$. The difference in the mean percentage score in practice regarding $\mathrm{FH}$ between the two groups was 14.74 (95\% Cl: $7.05,22.44)$. The results are shown in Table 3.

\section{PLEASE INSERT TABLE 3 HERE}

Regarding awareness, the median percentage score was significantly higher in PCP-PG-Qual (15.4, IqR \pm 23.08) compared to PCP-noPG-Qual (7.7, lqR \pm 15.38$), p=0.030$. The difference in the median percentage score in awareness regarding $\mathrm{FH}$ between the two groups was 7.69. The results are shown in Table 4.

\section{PLEASE INSERT TABLE 4 HERE}


The KR-20 internal consistency reliability coefficient of the FH KAP questionnaire was $0.53,0.76$ and 0.61 for knowledge, awareness and practice domains, respectively. The overall KR-20 coefficient for the FH KAP questionnaire was 0.79 which indicated moderate reliability [29]. The internal consistency reliability results of the FH KAP questionnaire are shown in Table 5.

\section{PLEASE INSERT TABLE 5 HERE}

\section{Test-retest reliability using Cohen's kappa statistics}

Out of 130 participants, $26(20 \%)$ participants completed the questionnaire again at two weeks interval. The kappa values were $0.818,0.810$ and 0.760 for knowledge, awareness and practice domains, respectively. The average kappa value for the FH KAP questionnaire was 0.796 , which indicated substantial agreement [30]. The test-retest reliability results of the FH KAP questionnaire are shown in Table 6.

\section{PLEASE INSERT TABLE 6 HERE}

This study has produced a valid and reliable 25 -item FH KAP questionnaire, and the final version is supplied in Supplementary File 3.

\section{Discussion}

To the best of our knowledge, this is the first study in Malaysia which has adapted a questionnaire to assess KAP among PCP to suit the local primary care setting. Malaysian PCP are ideally placed at the front line of care to play a pivotal role in detecting and managing FH in the community. However, implementation strategies for improving early diagnosis and care of $\mathrm{FH}$ in the community require adequate knowledge, awareness and appropriate practices among the PCP concerning the condition [26]. Therefore, the novel adaptation and validation of the FH KAP questionnaire in this study is crucial in order to produce a valid and reliable tool to assess KAP regarding FH among Malaysian PCP.

The adapted and validated FH KAP questionnaire consisted of 11 knowledge items, 5 awareness items and 9 practice items, giving a total of 25 items. In comparison to the study by Batais et al.,, the same questionnaire was adapted among their population into 23 items which encompassed 9 knowledge items, 5 awareness items and 9 practice items [24].

Overall, 10 items remained unchanged, 1 item was moved to demography, 8 items were modified or rephrased and 7 new items were added during the content validation and adaptation process. With regards to the knowledge domain, 3 items remained unchanged, 1 item was modified, 3 were rephrased for clarity and 4 items were added, giving a total of 11 items. The item assessing knowledge on prevalence of FH in Australia was found to be irrelevant to our PCP population and was therefore 
modified to global prevalence of $\mathrm{FH}$. The prevalence of $\mathrm{FH}$ in the Malaysian population was not known at the time of adaptation of this questionnaire in 2016, and therefore the panel felt that it was appropriate to assess the PCP knowledge on the global prevalence. The literature estimating the prevalence of clinically diagnosed FH at 1 in 100 was only published in 2018 [8]. Similar to the study in Saudi Arabia by Batais et al., the same item was changed to the global $\mathrm{FH}$ prevalence as the $\mathrm{FH}$ prevalence in their population was also unknown [24]. The four additional items included knowledge on target LDL-c level in FH, knowledge on the important of family history in $\mathrm{FH}$, exclusion of $\mathrm{FH}$ diagnosis as well as options in the $\mathrm{FH}$ management. They were added to ensure broader coverage of FH knowledge assessment among Malaysian PCP.

Concerning the awareness domain, 2 items remained unchanged, 1 item was modified and 2 items were added, giving a total of 5 items. The item assessing awareness of the Australian FH guideline was modified to awareness of the UK National Institute for Health and Care Excellence (NICE) FH Guideline 2008 [38]. The experts perceived that the awareness of the NICE FH guideline was appropriate as Malaysian PCP were thought to be more familiar with the UK-based guideline in the absence of a local Malaysian guideline on $\mathrm{FH}$. An item assessing the awareness of other international $\mathrm{FH}$ guidelines also was added i.e. International FH Foundation Guideline 2014 [39], the European Atherosclerosis Society (EAS) FH Guideline 2014 [40], the Japanese FH Guideline 2012 [41] and the American National Lipid Association (NLA) FH Guideline 2011 [42]. The addition was considered important as it would broaden the scope of assessment of PCP's awareness on other international FH guidelines apart from the NICE guideline. Another item to assess PCP's awareness of FH diagnostic criteria i.e. Simon Broome Register (SBR) Criteria [43], Dutch Lipid Clinic Network (DLCN) Criteria [44] and the United States (US) Make Early Diagnosis to Prevent Early Deaths (MED-PED) Criteria [45] was also added. This was crucial as these criteria would be useful in detection and diagnosis of $\mathrm{FH}$, and would be relevant to our PCP. The SBR Criteria was identified to perform better in detecting $\mathrm{FH}$ cases among Malaysian population compared to DLCN and US MED-PED Criteria as evidenced by a recent local study by Abdul-Razak et al. [46].

Regarding the practice domain, 5 items remained unchanged, 1 was moved to demography, 3 items were rephrased for clarity and 1 item was added, giving a total of 9 items. The item assessing the number of FH patients under care was moved to demography, as it was perceived to fit better in the demographic section. An item assessing practice in CAD risk stratification among $\mathrm{FH}$ patients was added. This is crucial as FH is known to carry a high mortality risk from CAD thus it is pivotal to assess whether PCP would still risk stratify patients with $\mathrm{FH}$. Risk stratification in patients with $\mathrm{FH}$ is not recommended as they should be classified as high risk irrespective of other risk factors [47].

With regards to construct validity, known-groups validation was conducted in view of the dichotomous nature of the responses in the FH KAP questionnaire [28]. Exploratory factor analysis which is commonly used for numerical or continuous responses items is not recommended to assess construct validity of a questionnaire which is dichotomously scored [28]. In this study, PCP-PG-Qual had significantly higher mean percentage scores for knowledge and practice compared with PCP-noPG-Qual. Similar trend was also found with regards to the median percentage score for awareness. This is in keeping with the 
hypothesis of this study where PCP-PG-Qual was expected to perform better in all KAP domains. This finding indicated that the adapted 25-item FH KAP questionnaire was a valid tool to be used for determination of FH KAP among PCP in Malaysia. Furthermore, the second part of our study which had used the 25-item adapted and validated questionnaire to determine the FH KAP among Malaysian PCP showed substantial gaps in FH-KAP among Malaysian PCP, with PCP-PG-Qual having better knowledge, awareness and practice than PCP-noPG-Qual [27].

Regarding internal consistency, the KR-20 reliability coefficient which is an alternative to Cronbach's alpha was carried out in this study because of the dichotomous nature of the questionnaire responses [29]. The KR-20 internal consistency coefficients for all the three domains showed moderate reliability (knowledge: 0.53 , awareness: 0.76 and practice: 0.61 ). The overall KR-20 for the FH KAP questionnaire also showed moderate reliability at 0.79 [29]. Direct comparison with other studies assessing the FH KAP questionnaire could not be made as none of the other studies used KR-20 internal consistency reliability. Batais et al. reported Cronbach's alpha value of $>7.0$ instead of KR-20 in their study [24]. However, the use of this particular method was not justified by the authors [24].

Regarding test-retest reliability analysis, Cohen's kappa coefficient was appropriately used instead of intra-class correlation coefficient (ICC) in view of the dichotomous nature of the questionnaire responses [30]. Cohen's kappa statistic is a form of reliability coefficient to determine the degree of agreement between two different evaluations from dichotomous variables [30]. In this study, the kappa values were almost perfect for the knowledge (0.818) and awareness (0.810) domains while the practice domain showed substantial agreement $(0.760)$. The average kappa coefficient of the FH KAP questionnaire was 0.796, indicating substantial agreement [30]. Therefore, this questionnaire was considered reliable and stable over time to be used among Malaysian PCP. In comparison to the study by Batais et al.,n they reported an average kappa of 0.85 [24], which was comparable to our study.

\section{Strength and limitation}

The strength of this study included the robust adaptation and validation methods used to determine the validity and reliability of this questionnaire among the Malaysian PCP. The adapted and validated 25 -item questionnaire is more comprehensive as it contains areas of $\mathrm{FH}$ care not included in the original 19-item questionnaire. These include pertinent areas such as assessing awareness of $\mathrm{FH}$ diagnostic criteria and assessing practice on CAD risk stratification for $\mathrm{FH}$ patients.

There were several inevitable limitations in this study which include the low response rate, which is expected for an online questionnaire disseminated through emails [34]. However, the sample size for psychometric evaluation was adequate to ensure validity and reliability of the FH KAP questionnaire in this study. Another limitation was the possibility of response bias in this study. The self-selected group that responded to the questionnaire may reflect those with more interest and knowledge in lipid disorders. The use of online questionnaire was also vulnerable to response bias in which the PCP could get the information easily from the internet. It is well recognised that a more representative and unbiased 
sampling method would be to conduct a multistage probability sampling which would give all the PCP in Malaysia an equal chance to be selected.

\section{Implications for future research and clinical practice}

This study has produced a valid and reliable paper-based as well as online version of the questionnaire which can be used to determine the KAP regarding FH among PCP in Malaysia. However, it is recommended that researchers should at least perform the KR-20 internal consistency analysis to ensure that the questionnaire is reliable in their respective populations. To ensure representative and unbiased sampling, future research should be conducted using a multistage probability sampling which would give all the PCP in Malaysia an equal chance to be selected. Future research should also consider conducting a qualitative study to explore barriers and facilitators regarding $\mathrm{FH}$ care in the Malaysian primary care settings. Further research should also evaluate the resource implication to improve $\mathrm{FH}$ care in the community including the pathways of referral for genetic testing. All of these research evidence are pertinent to support development of a national $\mathrm{FH}$ clinical practice guideline and $\mathrm{FH}$ training module for the Malaysian PCP.

\section{Conclusion}

This was the first study which adapted and validated an FH KAP questionnaire among PCP in Malaysia. The robust validation methods and their findings suggested that the adapted 25-item FH KAP questionnaire was a valid and reliable tool which can be used to measure FH KAP among Malaysian PCP. This would allow us to identify gaps in KAP regarding FH among those with and without PG qualifications in primary care. Subsequently, national FH clinical practice guideline and training module to address these gaps among Malaysian PCP should be developed. These strategies are imperative if we were to improve early detection, diagnosis and care of FH in the community, which in turn would enhance opportunities for premature CAD prevention.

\section{List Of Abbreviations}

FH = Familial Hypercholesterolaemia

LDL-C = low density lipoprotein cholesterol

$\mathrm{CAD}=$ coronary artery disease

$\mathrm{HeFH}=$ heterozygous $\mathrm{FH}$

$\mathrm{HoFH}=$ homozygous $\mathrm{FH}$

ACS $=$ acute coronary syndrome 
PCP = Primary care physicians

$P G=$ postgraduate

UK = United Kingdom

$\mathrm{KAP}=$ knowledge, awareness and practice

$\mathrm{MO}=$ medical officers

$\mathrm{GP}=$ general practitioners

FMS = Family Medicine Specialists

PCP-PG-Qual = PCP with postgraduate qualification

DFM = Diploma in Family Medicine

FRACGP $=$ Fellow of the Royal Australian College of General Practitioners

MRCGP, UK = Membership of the Royal College of General Practitioners, UK

PCP-noPG-Qual = PCP without postgraduate qualification

MBBS = Bachelor of Medicine, Bachelor of Surgery

$\mathrm{MD}=$ Doctor of Medicine

$\mathrm{KR}-20=$ Kuder Richardson formula -20

REC = Research Ethics Committee

SD = standard deviation

$\mathrm{df}=$ degree of freedom

$\mathrm{Cl}=$ confidence interval

$\mathrm{lqR}=$ inter quartile range

NICE = National Institute for Health and Care Excellence

EAS = European Atherosclerosis Society

NLA = National Lipid Association

SBR = Somon Broome Register 
DLCN = Dutch Lipid Clinic Network

US = United States

MED-PED = Make Early Diagnosis to Prevent Early Deaths

\section{Declarations}

\section{Ethics approval and consent to participate}

The study protocol and both the paper-based and online versions of the FH KAP questionnaire were reviewed and approved by the Research Ethics Committee (REC), Universiti Teknologi MARA (600-IRMI $(5 / 1 / 6)$. The designing of the online survey questionnaire using the Google® Forms complied with the British Psychological Society (2013), Ethics Guidelines for Internet-Mediated Research [37]. Information about the study and participant's right to withdraw from the study at any time was provided in the English language on the front page of the paper-based and online versions of the questionnaire. Informed consent was obtained when participants clicked on the consent button in order to proceed to the various sections of the questionnaire. The data collected was kept anonymous as IP address was not collected. Confidentiality was ensured by keeping a single account protected by a password which was only known to the researcher and data was not stored within a shared Google® Forms account.

\section{Consent for publication}

Written permission was obtained from the original developer of the FH KAP questionnaire (GFW) to adapt and validate this questionnaire in Malaysian PCP. Permission was also obtained to publish the finding. Participants' consent for publication is not applicable as participants' individual data was neither provided nor presented in the manuscript.

\section{Availability of data and material}

Data are kept at the Institute of Pathology, Laboratory and Forensic Medicine (IPPerForM), Universiti Teknologi MARA (UiTM), Sungai Buloh Campus, Jalan Hospital, 47000 Sungai Buloh, Selangor, Malaysia. Data will be shared upon request and is subjected to the data protection regulations.

\section{Competing interest}

All authors declare that they have no competing interests.

\section{Funding}


The Asia Pacific Translational Research for Improving the Care of Familial Hypercholesterolaemia: FH 'Ten Countries Study' was supported and funded by a Pfizer/International Atherosclerosis Society (IAS) Grant to the Asian-Pacific Society of Atherosclerosis and Vascular Disease (APSAVD) - Chief Investigator GFW, University of Western Australia (UWA), Australia. The Malaysian component of the FH KAP study was also funded by this grant, awarded to $\mathrm{HN}$ as the Principal Investigator for Malaysia (Grant Code:100RMI/INT 16-/6/2(3/2015), in addition to the Universiti Teknologi MARA (UiTM) LESTARI Research Grant, Malaysia, grant code: 600-IRMI/DANA 5/3/LESTARI (0161/2016), awarded to ASR. The funding body did not play any role in the design of the study, or in data collection, analysis or interpretation, or in writing the manuscript.

\section{Authors' contributions}

GFW, HN, ASR, ZI and ABA conceptualized and designed the study. ASR, HN and ZI acquired the funding. ASR, HN and ZI supervised and coordinated the study. SAR and NA facilitated the data collection. ABA, SAR and NAMK acquired the data. ABA and ZI analysed and interpreted the data. SFB gave critical input regarding the validation methods. ABA and ASR drafted the manuscript. All authors revised the manuscript critically for important intellectual content. All authors have read and given approval of the final manuscript. Each author has participated sufficiently in the work to take public responsibility for appropriate portions of the content as described above. All authors agreed to be accountable for all aspects of the work to ensure that questions related to the accuracy or integrity of any part of the work would be appropriately investigated and resolved.

\section{Acknowledgements}

This study was undertaken under the aegis of the FH-'Ten Countries Study' supported by the AsianPacific Society of Atherosclerosis and Vascular Disease (APSAVD) and the International Atherosclerosis Society (IAS). The authors wish to thank Dr. Norsiah Ali, the President of Family Medicine Specialist Association (FMSA) and Associate Professor Dr. Mohammad Husni Jamal, the President of the Academy of Family Physicians Malaysia (AFPM) for facilitating the data collection from members of the associations. The authors also wish to thank Dr. Thuhairah Hasrah Abd. Rahman and Nurul Atiqah Mohd Mokhsin for their assistance in the questionnaire adaptation and data collection during the early part of the study. Our gratitude also goes to Dr. Mohamad Rodi Isa for his advice on the statistical analysis.

\section{References}

1. Najam O, Ray KK. Familial Hypercholesterolemia: a review of the natural history, diagnosis, and management. Cardiol Ther. 2015;4(1):25-38. doi:10.1007/s40119-015-0037-z.

2. Austin MA, Hutter CM, Zimmern RL, Humphries SE. Genetic causes of monogenic heterozygous familial hypercholesterolemia: a HuGE prevalence review. Am J Epidemiol. 2004;160:407-20. doi:10.1093/aje/kwh236. 
3. De Castro-Orós I, Pocoví M, Civeira F. The genetic basis of familial hypercholesterolemia: inheritance, linkage, and mutations. Appl Clin Genet. 2010;3:53-64.

4. Elis A, Zhou R, Stein EA. Effect of lipid-lowering treatment on natural history of heterozygous familial hypercholesterolemia in past three decades. Am J Cardiol. 2011;108:223-6.

5. Bertolini S, Pisciotta L, Rabacchi C, Cefalù AB, Noto D, Fasano T, Signori A, Fresa R, Averna M, Calandra S. Spectrum of mutations and phenotypic expression in patients with autosomal dominant hypercholesterolemia identified in Italy. Atherosclerosis. 2013;227:342-8.

6. Shi Z, Yuan B, Zhao D, Taylor AW, Lin J, Watss GF. Familial hypercholesterolemia in China: prevalence and evidence of underdetection and undertreatment in a community population, Int. J. Cardiol. 2014;174(3):834-6. doi:10.1016/j.ijcard.2014.04.165.

7. Watts GF, Shaw JE, Pang J, Magliano DJ, Jennings GLR, Carrington MJ. Prevalence and treatment of familial hypercholesterolaemia in Australian communities. Int J Cardiol. 2015;185:69-71. doi:10.1016/j.ijcard.2015.03.027.

8. Vallejo-Vaz AJ, De Marco M, Stevens CAT, Akram A, et al. Overview of the current status of familial hypercholesterolaemia care in over 60 countries - The EAS Familial Hypercholesterolaemia Studies Collaboration (FHSC). Atherosclerosis. 2018;277:234-55. doi.org/10.1016/j.atherosclerosis.2018.08.051.

9. Neil HAW, Hammond T, Huxley TR, Matthews DR, Humphries SE. Extent of underdiagnosis of familial hypercholesterolaemia in routine practice: prospective registry study. BMJ. 2000; 321:148. doi:10.1136/bmj.321.7254.148.

10. Brett T, Watts GF, Arnold-Reed DE, Bell DA, Garton-Smith J, Vickery AW, Ryan JD, Pang J. Challenges in the care of familial hypercholesterolemia: a community care perspective. Expert Rev Cardiovasc Ther. 2015;13:1091-100. doi:10.1586/14779072.2015.1082907.

11. Shah SA, Jing L, Khalid MS, Najid F, Haniff IS, Mohd-Ghazi A, Mohd-Nor IF, Mohd-Ali R, Wan-Ngah WZ. Prevalence and risk factors of premature coronary artery disease: A comparative cross-sectional study between two time frames in Malaysia. Malaysian Journal of Public Health Medicine. 2015;15(3):157-66.

12. National Heart Association and Ministry of Health Malaysia. Annual Report of the NCVD-ACS Registry 2014-2015. https://www.malaysianheart.org/files/5ae6b04 77ed84.pdf

13. Ueshima H, Sekikawa A, Miura K, Turin TC, Takashima N, et al. Cardiovascular disease and risk factors in Asia: a selected review. Circulation. 2008;118(25):2702-9. doi:10.1161/CIRCULATIONAHA.108.790048

14. Nordestgaard BG, Chapman MJ, Humphries SE, Ginsberg HN, Masana L, et al. Familial hypercholesterolaemia is underdiagnosed and undertreated in the general population: guidance for clinicians to prevent coronary heart disease: consensus statement of the European Atherosclerosis Society. Eur Heart J. 2013;34:3478-90a. doi:10.1093/eurheartj/eht273.

15. Clinical Research Centre, Ministry of Health, Malaysia. National Healthcare Establishments and Workforce Statistics (Primary Care) 2008-2009, Kuala Lumpur, 2011. 
http://www.crc.gov.my/nhsi/wp-content/uploads/document/publication/Primary_Care_Report.pdf.

16. Ramli AS, Taher SW. Managing chronic diseases in the Malaysian primary health care-a need for change. Malaysian Family Physician. 2008; 3(1):7-13.

17. Chan TK, Lee CY, Yau SK, Tipoe GL. Primary care in Asia: a call forcompulsory vocational training. $\mathrm{Br}$. J. Gen. Pract. 2014;64 (623):e381-e383. doi.org/ 10.3399/bjgp14X680281.

18. Bell DA, Garton-Smith J, Vickery A, Kirke AB, Pang J, et al. Familial hypercholesterolaemia in primary care: knowledge and practices among general practitioners in Western Australia. Heart Lung Circ. 2014;23(4):309-13. doi:10.1016/j.hlc.2013.08.005.

19. Kirke AB, Barbour RA, Burrows S, Bell DA, Vickery AW, Emery J, Watts GF. Systematic detection of familial hypercholesterolaemia in primary health care: a community based prospective study of three methods. Heart Lung Circ. 2015;24(3):250-6. doi:10.1016/j.hlc.2014.09.011.

20. Pang J, Sullivan DR, Harada-Shiba M, Ding PY, Selvey S, et al. Significant gaps in awareness of familial hypercholesterolemia among physicians in selected Asia-Pacific countries: a pilot study. $J$ Clin Lipidol. 2015;9(1):42-8. doi:10.1016/j.jacl.2014.09.011.

21. Kwok S, Pang J, Adam S, et al. An online questionnaire survey of UK general practitioners' knowledge and management of familial hypercholesterolaemia. BMJ Open. 2016;6:e12691. doi:10.1136/bmjopen-2016-012691.

22. Schofield J, Kwok S, France M, Capps N, Eatough R, Yadav R, Ray K, Soran H. Knowledge gaps in the management of familial hypercholesterolaemia. A UK based survey. Atherosclerosis. 2016; 252:1615. doi: 10.1016/j.atherosclerosis.2016.07.009.

23. Rangarajan N, Balasubramanian S, Pang J, Watts GF. Knowledge and awareness of familial hypercholesterolaemia among registered medical practitioners in Tamil Nadu: are they suboptimal? J Clin Diagn Res. 2016;10(5): OC52-6. doi:10.7860/JCDR/2016/18798.7893.

24. Batais MA, Almigbal TH, Abdulhak AA, Altaradi HB, AlHabib KF. Assessment of physicians' awareness and knowledge of familial hypercholesterolemia in Saudi Arabia: is there a gap? PLoS One. 2017;12:e0183494. doi:10.1371/journal.pone.0183494.

25. Pang J, Hu M, Lin J, Miida T, Nawawi HM, Park JE, Wu X, Ramli AS, Kim NT, Kwok S, et al. An enquiry based on on a standardised questionnaire into knowledge, awareness and preferences concerning the care of familial hypercholesterolaemia among primary care physicians in the Asia-Pacific region: the "Ten Countries Study". BMJ Open. 2017;7(10):e017817. doi:10.1136/bmjopen-2017-017817.

26. Jones LK, Gidding SS, Seaton TL, Goldberg A, Gregor C, Sturm AC, Brownson RC, Rahm AK, Williams MS. Developing implementation strategies to improve uptake of guideline-recommended treatments for individuals with familial hypercholesterolemia: A protocol. Res Social Adm Pharm. 2019;S15517411(19)30458-9. doi:10.1016/j.sapharm.2019.06.006.

27. Azraii AB, Ramli AS, Ismail Z, Abdul-Razak S, Mohd-Kasim NA, Ali N, Watts GF, Nawawi H. Knowledge, awareness and practice regarding familial hypercholesterolaemia among primary care physicians in Malaysia: The importance of professional training. Atherosclerosis. 2018;277:508-16. doi:10.1016/j.atherosclerosis.2018.08.018. 
28. Hattie J, Cooksey RW. Procedures for assessing the validities of tests using the "Known-Groups" method. Applied Psychological Measurement. 1984;8(3):295-305.

doi:10.1177/014662168400800306

29. Ş. Tan. Misuses of KR-20 and Cronbach's alpha reliability coefficients. Education and Science. 2009;34(152):101-12.

30. Sim J, Wright CC. The kappa statistic in reliability studies: use, interpretation, and sample size requirements. Physical Therapy. 2005;85(3):257-68. doi:10.1093/ptj/85.3.257.

31. Google® Forms: Free Online Surveys. https://www.google.com/forms/about/

32. OpenEpi sample size software for comparing two means. https://www.openepi.com/SampleSize/SSMean.htm

33. Mosli M, Alnahdi Y, Alghamdi A, Baabdullah M, Hadadi A, Khateery K, et al. Knowledge, attitude, and practices of primary health care physicians toward colorectal cancer screening. Saudi $J$ Gastroenterol. 2017;23(6):330-6.

34. Yan Z, Fan W. Factors affecting response rates of the web survey: A systematic review. Computers in Human Behaviors. 2010;26:132-39. doi:10.1016/j.chb.2009.10.015.

35. Bujang $M$, Baharom N. Guidelines of the minimum sample size requirements for kappa agreement test. Epidemiology Biostatistics and Public Health. 2017;14(2):e12267. doi:10.2427/12267.

36. IBM. Kuder-Richardson reliability coefficients KR20 and KR2. IBM Support (Online). https://www01.ibm.com/

37. British Psychological Society. Ethics Guidelines for Internet-mediated Research. INF206/1.2013. Leicester, 2013. https://www.bps.org.uk/files/ethics-guidelines-internet-mediated-research-2013pdf.

38. National Institute for Health and Care Excellence (NICE). Identification and Management of Familial Hypercholesterolaemia (CG71), 2008. Last updated 2017. https://www. nice.org.uk/guidance/cg71.

39. Watts GF, Gidding S, Wierzbicki AS, et al. Integrated guidance on the care of familial hypercholesterolaemia from the International FH Foundation. Int J Cardiol. 2014;171:309-25. doi:10.1016/j.ijcard.2013.11.025.

40. Cuchel M, Bruckert E, Chapman MJ, Descamps OS, Ginsberg HN, Hegele RA, et.al. Homozygous familial hypercholesterolaemia: new insights and guidance for clinicians to improve detection and clinical management. A position paper from the Consensus Panel on Familial Hypercholesterolaemia of the European Atherosclerosis Society. Eur Heart J. 2014; 35(32):2146-57. doi:10.1093/eurheartj/ehu274.

41. Harada-Shiba M, Arai H, Oikawa S, Ohta T, Okada T, Okamura T, Nohara A, Bujo H, Koutaro Yokote, Wakatsuki A, Ishibashi S, Yamashita S. Guidelines for the Management of Familial Hypercholesterolemia. Journal of Atherosclerosis and Thrombosis. 2012;19(12):1043-60. doi:10.5551/jat.14621.

42. Goldberg AC, Hopkins PN, Toth PP, Ballantyne CM, Rader DJ, Robinson JG, Daniels SR, Gidding SS, de Ferranti SD, Ito MK, McGowan MP, Moriarty PM, Cromwell WC, Ross JL, Ziajka PE. Familial hypercholesterolemia: screening, diagnosis and management of pediatric and adult patients: clinical 
guidance from the National Lipid Association Expert Panel on Familial Hypercholesterolemia. J Clin Lipidol. 2011;5(3 Suppl):S1-8. doi:10.1016/j.jacl.2011.04.003.

43. Scientific Steering Committee on behalf of the Simon Broome Register Group. Risk of fatal coronary heart disease in familial hypercholesterolaemia. BMJ. 1991;303(6807):893-6. doi:10.1136/bmj.303.6807.893

44. Reiner Z, Catapano AL, De Backer G, Graham I, Taskinen M-R, Wiklund O, et al. ESC/EAS guidelines for the management of dyslipidaemias: the task force for the management of dyslipidaemias of the European Society of Cardiology (ESC) and the European atherosclerosis society (EAS). Eur Heart J. 2011;32(14):1769-818. doi: 10.1093/eurheartj/ehr158.

45. Williams RR, Hunt SC, Schumacher MC, Hegele RA, Leppert MF, Ludwig EH, et al. Diagnosing heterozygous familial hypercholesterolemia using new practical criteria validated by molecular genetics. Am J Cardiol. 1993;72(2):171-6. doi:10.1016/0002-9149(93)90155-6.

46. Abdul-Razak S, Rahmat R, Mohd Kasim A, Rahman TA, Muid S, et al. Diagnostic performance of various familial hypercholesterolaemia diagnostic criteria compared to Dutch Lipid Clinic criteria in an Asian population. BMC Cardiovasc Disord. 2017;17(1):264. doi:10.1186/s12872-017-0694-z.

47. Sharifi M, Rakhit RD, Humphries SE, Nair D. Cardiovascular risk stratification in familial hypercholesterolaemia. Heart. 2016; 102(13):1003-8. doi:10.1136/heartjnl-2015-308845.

\section{Tables}

Table 1: Summary of adaptation of the FH KAP questionnaire 
Item No. Original 19-Item FH KAP Questionnaire

Knowledge Domain

3 Description of $\mathrm{FH}$

$4 \quad$ Lipid profile in $\mathrm{FH}$

6 Prevalence of FH in Australia

7 Inheritance of $\mathrm{FH}$

8 CAD risk in $\mathrm{FH}$

9 Age threshold for premature CAD

11 Genetic test in $\mathrm{FH}$

22

23

24

25

Total items: 7

\section{Awareness Domain}

$1 \quad$ Familiarity with $\mathrm{FH}$

2 Awareness of Australian FH guideline

16 Awareness of lipid specialist service 19

20

Total items: 3
Adapted 25-Item FH KAP

Questionnaire

Question rephrased

Answer rephrased

Modified to prevalence of FH globally

No change

No change

Question rephrased

No change

Added: Target LDL-c in FH

Added: Family history in $\mathrm{FH}$

Added: Exclusion of FH diagnosis

Added: Management options in FH

Total items: 11

No change

Modified to awareness of NICE FH guideline

No change except for question number

Added: Awareness of FH diagnostic criteria

Added: Awareness of other FH guidelines

Total items: 5

\section{Practice Domain}

\section{Assistance in $\mathrm{FH}$ detection}

10 Family screening of $\mathrm{FH}$

12 Number of FH patients under care

13 Screening of relatives in $\mathrm{FH}$

14 Effective healthcare provider in $\mathrm{FH}$

15 Age for FH screening in young individuals

17 Referral to lipid specialist

18 Pharmacotherapy used in hypercholesterolaemia

19 Combined pharmacotherapy used in severe hypercholesterolaemia
No change

Question rephrased

Moved to demography

No change

No change

No change

No change except for question number

Question rephrased

Question rephrased

Added: CAD risk stratification in $\mathrm{FH}$

Total items: 9

Total items: 9 
Abbreviations: $F H$, familial hypercholesterolaemia; $C A D$, coronary artery disease; $L D L-C$, low density lipoprotein cholesterol; $N I C E$, National Institute for Health and Care Excellence;

Table 2: Demographic characteristics and practice details of the study participants

\begin{tabular}{|c|c|c|c|}
\hline \multirow[t]{2}{*}{ Characteristics of Participants } & $\begin{array}{l}\text { PCP-PG-Qual } \\
\text { n (\%) }\end{array}$ & $\begin{array}{l}\text { PCP-noPG-Qual } \\
n(\%)\end{array}$ & $\begin{array}{l}\text { Total PCP } \\
\text { n (\%) }\end{array}$ \\
\hline & $31(23.8)$ & $99(76.2)$ & $n=130(100)$ \\
\hline \multicolumn{4}{|l|}{ Gender } \\
\hline Male & $7(22.6)$ & $30(30.3)$ & \multirow{2}{*}{$\begin{array}{l}37(28.5) \\
93(71.5)\end{array}$} \\
\hline Female & $24(77.4)$ & $69(69.7)$ & \\
\hline \multicolumn{4}{|l|}{ Practice } \\
\hline Ministry of Health & $15(48.4)$ & $56(56.6)$ & $71(54.6)$ \\
\hline Ministry of Defence & & $2(2)$ & $2(1.5)$ \\
\hline University & $10(32.3)$ & $22(22.2)$ & $32(24.6)$ \\
\hline Private services & $6(19.4)$ & $19(19.2)$ & $25(19.2)$ \\
\hline Location & & & \multirow[b]{2}{*}{$33(25.4)$} \\
\hline Rural & $4(12.9)$ & $29(29.3)$ & \\
\hline Urban & $27(87.1)$ & $70(70.7)$ & $97(74.6)$ \\
\hline \multicolumn{4}{|l|}{ Qualification } \\
\hline Basic medical degree (only) & 0 & $99(100)$ & $99(76.2)$ \\
\hline Diploma in Family Medicine & $15(48.4)$ & 0 & $15(11.5)$ \\
\hline Master of Family Medicine & $15(48.4)$ & 0 & \multirow{2}{*}{$\begin{array}{l}15(11.5) \\
1(0.8)\end{array}$} \\
\hline Fellow of Royal Australian College of GP & $1(3.2)$ & 0 & \\
\hline Member of Royal College of GP (UK) & 0 & 0 & 0 \\
\hline \multicolumn{4}{|l|}{ Service Duration } \\
\hline$<5$ years & $9(29)$ & $20(20.2)$ & $29(22.3)$ \\
\hline $5-10$ years & $14(45.2)$ & $53(53.5)$ & $67(51.5)$ \\
\hline$>10$ years & $6(19.4)$ & $24(24.2)$ & $30(23.1)$ \\
\hline No response & $2(6.5)$ & $2(2)$ & $4(3.1)$ \\
\hline \multicolumn{4}{|l|}{ Patients Seen per Month } \\
\hline$<500$ patients & $22(71)$ & $41(41.4)$ & \\
\hline $500-1000$ patients & $5(16.1)$ & $37(37.4)$ & $42(32.3)$ \\
\hline > 1000 patients & $2(6.5)$ & $9(9.1)$ & $11(8.5)$ \\
\hline No response & $2(6.5)$ & $12(12.1)$ & $14(10.8)$ \\
\hline FH Patients Under Care & & & \multirow[b]{2}{*}{$80(61.5)$} \\
\hline No patient & $15(48.4)$ & $65(65.7)$ & \\
\hline $1-4$ patients & $11(35.5)$ & $13(13.1)$ & \\
\hline$>4$ patients & $2(6.5)$ & $5(5.1)$ & $7(5.4)$ \\
\hline No response & $3(9.7)$ & $16(16.1)$ & $19(14.6)$ \\
\hline
\end{tabular}

Abbreviations: $n$, number; $P C P-P G-Q u a l$, primary care physicians with postgraduate qualification; $P C P$ noPG-Qual, primary care physicians without postgraduate qualification; $F H$, familial hypercholesterolaemia; GP, general practitioners; UK, United Kingdom; 
Table 3: Known-groups validity by comparing mean percentage scores in knowledge and practice regarding FH between PCP-PG-Qual and PCP-noPG-Qual

\begin{tabular}{|c|c|c|c|c|c|}
\hline \multirow[t]{2}{*}{$\begin{array}{l}\text { KAP } \\
\text { Domain }\end{array}$} & Score of PCP-PG- & Score of PCP-noPG- & \multirow{2}{*}{$\begin{array}{l}\text { Mean Difference in } \\
\text { Percentage Score } \\
(95 \% \mathrm{Cl})\end{array}$} & \multirow{2}{*}{$\begin{array}{l}t \\
\text { value }^{a} \\
(d f)^{b}\end{array}$} & \multirow[t]{2}{*}{$\begin{array}{l}\text { p- } \\
\text { value }\end{array}$} \\
\hline & $\mathrm{n}=31$ & $\mathrm{n}=99$ & & & \\
\hline Knowledge & $53.5(13.99)$ & 35.9 (11.79) & 17.54 & 6.90 & $<0.001$ \\
\hline & & & $(12.52,22.57)$ & (128) & \\
\hline Practice & $69.2(17.62)$ & $54.4(19.28)$ & 14.74 & 3.79 & $<0.001$ \\
\hline & & & $(7.05,22.44)$ & (128) & \\
\hline
\end{tabular}

Abbreviations: $K A P$, knowledge, awareness and practice; $S D$, standard deviation; $d f$, degree of freedom; $C l$, confidence interval; $n$, number; $P C P-P G$-Qual, primary care physicians with postgraduate qualification; $P C P-n o P G-Q u a l$, primary care physicians without postgraduate qualification;

a Independent $t$-test was used to compare means as the data were normally distributed. The null hypothesis was rejected as the calculated $t$ value $>$ critical $t$ value.

${ }^{b} \mathrm{df}$ : degrees of freedom of the critical value of $t$

c Significant $p<0.05$

Table 4: Known-groups validity by comparing the median percentage score in awareness regarding FH between PCP-PG-Qual and PCP-noPG-Qual

\begin{tabular}{llllll}
\hline KAP & Median ( \pm lqR) & Median $( \pm$ lqR) Percentage & Median & z- & p- \\
Domain & Percentage Score of & Score of PCP-noPG- & Difference in & value $^{\text {a }}$ & value $^{\text {b }}$ \\
& PCP-PG-Qual $n=31$ & Qual $\quad n=99$ & Percentage & & \\
& & & & &
\end{tabular}

\begin{tabular}{llllll}
\hline Awareness & $15.4(23.08)$ & $7.7(15.38)$ & 7.69 & 2.17 & 0.030
\end{tabular}

\footnotetext{
Abbreviations: $K A P$, knowledge, awareness and practice; IqR, inter quartile range; $n$, number; $P C P-P G-$ Qual, primary care physicians with postgraduate qualification; $P C P$-noPG-Qual, primary care physicians without postgraduate qualification;

a Mann Whitney u-test was used to compare medians as the data was not normally distributed. The null hypothesis was rejected as the $z$ value was $>1.96$.

b Significant $p<0.05$
} 
Table 5: Internal consistency reliability of the FH KAP questionnaire

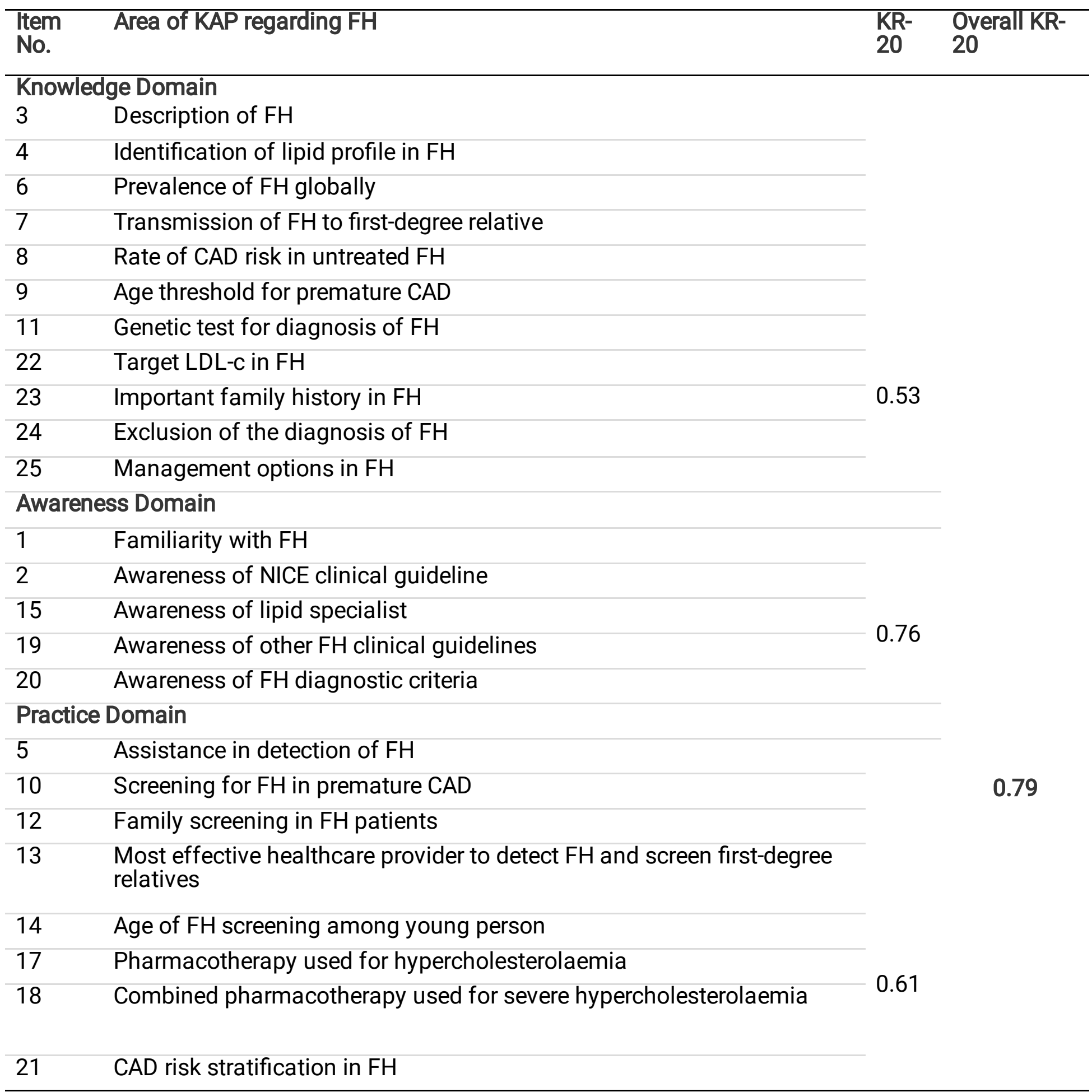

Abbreviations: $F H$, familial hypercholesterolaemia; $C A D$, coronary artery disease; $L D L-C$, low density lipoprotein cholesterol; $N I C E$, National Institute for Health and Care Excellence;

Table 6: Test-restest reliability of the FH KAP questionnaire 


\begin{tabular}{|c|c|c|c|c|}
\hline \multirow{2}{*}{\multicolumn{2}{|c|}{ Knowledge Domain }} & \multirow{2}{*}{\multicolumn{2}{|c|}{0.879}} & \\
\hline & & & & \\
\hline 4 & Identification of lipid profile in $\mathrm{FH}$ & \multicolumn{2}{|l|}{0.865} & \\
\hline 6 & Prevalence of FH globally & \multicolumn{2}{|l|}{0.759} & \\
\hline 7 & Transmission of FH to first-degree relative & \multicolumn{2}{|l|}{0.811} & \\
\hline 8 & Rate of CAD risk in untreated FH & \multicolumn{2}{|l|}{0.755} & \\
\hline $\begin{array}{l}9 \\
\text { (a) }\end{array}$ & Age for premature CAD (males) & \multicolumn{2}{|l|}{0.920} & \\
\hline \multirow{2}{*}{$\begin{array}{l}9 \\
\text { (b }\end{array}$} & Age for premature CAD (females) & 0.923 & 0.818 & \\
\hline & Genetic test for diagnosis of FH & \multicolumn{2}{|l|}{0.650} & \\
\hline 22 & Target LDL-c in FH & \multicolumn{2}{|l|}{0.854} & \\
\hline 23 & Important family history in FH & \multicolumn{2}{|l|}{0.695} & \\
\hline 24 & Exclusion of the diagnosis of $\mathrm{FH}$ & \multicolumn{2}{|l|}{0.869} & \\
\hline 25 & Management options in FH & \multicolumn{2}{|l|}{0.835} & \\
\hline \multicolumn{5}{|c|}{ Awareness Domain } \\
\hline 1 & Familiarity with $\mathrm{FH}$ & \multicolumn{3}{|l|}{0.819} \\
\hline 2 & Awareness of NICE clinical guideline & \multicolumn{3}{|l|}{0.769} \\
\hline 15 & Awareness of lipid specialist & \multicolumn{3}{|l|}{0.920} \\
\hline 19 & Awareness of other FH clinical guidelines & \multicolumn{3}{|l|}{0.648} \\
\hline 20 & Awareness of FH diagnostic criteria & \multicolumn{3}{|l|}{0.893} \\
\hline \multicolumn{5}{|c|}{ Practice Domain } \\
\hline 5 & Assistance in detection of $\mathrm{FH}$ & \multicolumn{3}{|l|}{0.877} \\
\hline 10 & Screening for $\mathrm{FH}$ in premature CAD & \multicolumn{3}{|l|}{0.641} \\
\hline 12 & Family screening in FH patients & \multicolumn{3}{|l|}{0.507} \\
\hline 13 & Most effective provider in $\mathrm{FH}$ detection & \multicolumn{3}{|l|}{0.622} \\
\hline 14 & Age of FH screening among young person & \multicolumn{3}{|c|}{$0.685 \quad 0.760$} \\
\hline 16 & Referral to lipid specialist & \multicolumn{3}{|l|}{1.000} \\
\hline 17 & Pharmacotherapy used for hypercholesterolaemia & \multicolumn{2}{|l|}{0.943} & 0.796 \\
\hline 18 & $\begin{array}{l}\text { Combined pharmacotherapy used for severe } \\
\text { hypercholesterolaemia }\end{array}$ & \multicolumn{2}{|l|}{0.692} & \\
\hline 21 & CAD risk stratification in $\mathrm{FH}$ & \multicolumn{3}{|l|}{0.872} \\
\hline
\end{tabular}

Abbreviations: $F H$, familial hypercholesterolaemia; $C A D$, coronary artery disease; $L D L-C$, low density lipoprotein cholesterol; $N I C E$, National Institute for Health and Care Excellence;

\section{Figures}




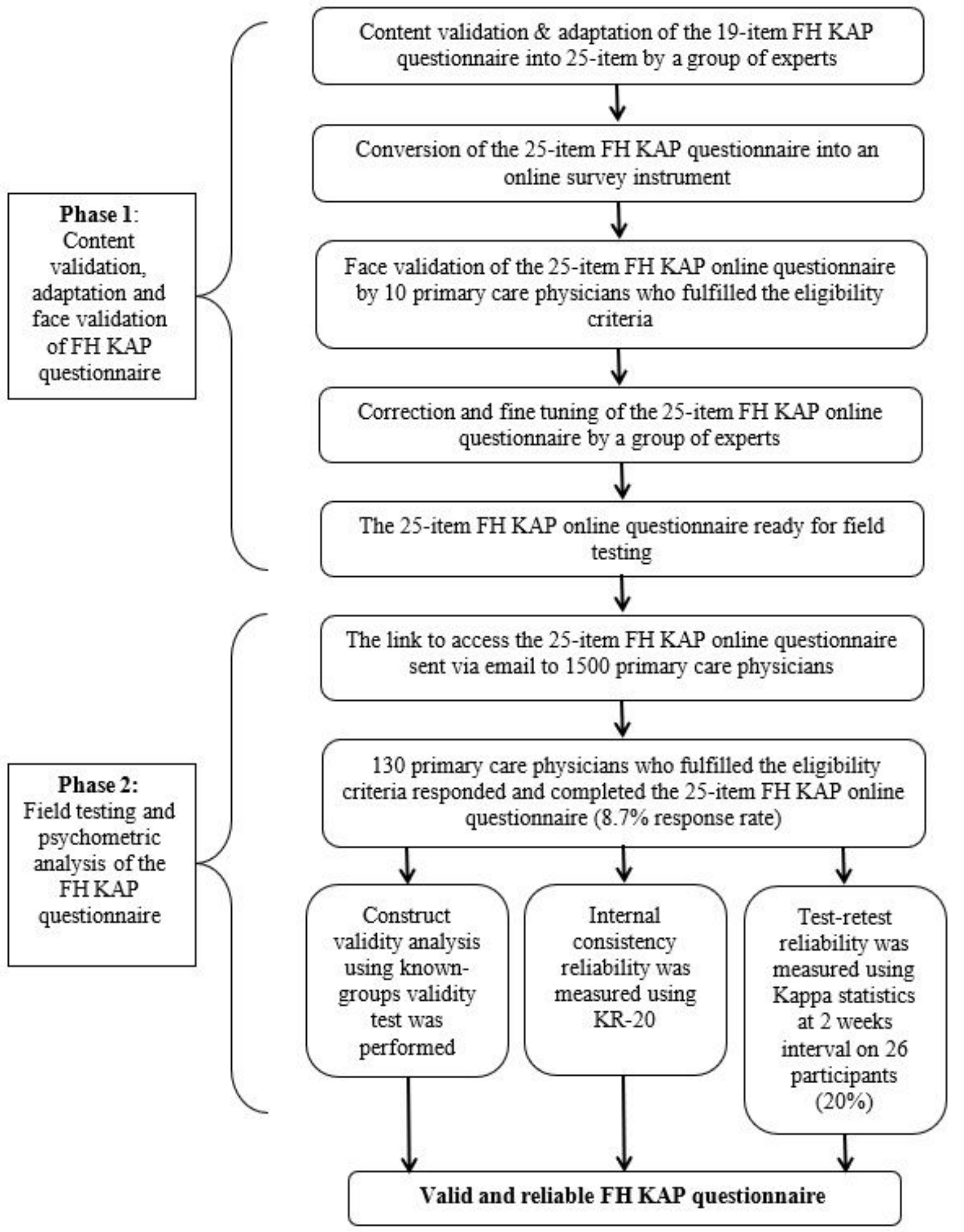

Figure 1

Flow chart of the conduct of the study

\section{Supplementary Files}

This is a list of supplementary files associated with this preprint. Click to download. 
- SupplementaryFile3TheFinal25ItemFHKAPQuestionnaire.doc

- SupplementaryFile2FHKAPQuestionnaireAdaptation.docx

- SupplementaryFile1FHKAPQuestionnaireScoring.docx 